\title{
ELABORACIÓN DEL PLAN DE NEGOCIOS PARA LOS FONDOS DE ALCACHOFA (Cynara scolymus) EN ALMIBAR
}

\section{ELABORATION OF A BUSINESS PLAN FOR ARCHITOKE BOTTOM (Cynara scolymus) IN SYRUP}

\author{
Carlos G. Seguil Mirones', Enma E. Egas Peña²
}

\section{RESUMEN}

Se identificó un segmento de mercado que valora a la alcachofa, por lo cual se elaboró el plan de negocios, que nos permitió evaluar las posibilidades de éxito de la idea de negocio. Se determinó que el segmento de mercado para este producto, se encuentra en los estratos socioeconómicos $A$ y $B$ de las provincias de Lima y Callao, que representa 7 551370 habitantes, en el año 2005, el mercado disponible calificado 1056587 habitantes, que se encuentran en los distritos más representativos: Santiago de Surco, Lima, San Borja, San Miguel, Miraflores, Pueblo Libre, Jesús María, La Molina, San Isidro, La Victoria y Lince. El mercado penetrado representará el 10\%, teniendo una demanda insatisfecha de 8,5 TM de producto final al año. La decisión del mix de mercadeo es el siguiente: Producto, fondos de alcachofa en almíbar en frascos de $250 \mathrm{~g}$. de capacidad, precio S/. 3,50 por frasco, plaza exclusiva en los supermercados E. Wong y Santa Isabel, promoción con Impulsadoras en los puntos de venta.

Palabras clave: Plan de negocio, alcachofa, investigación de mercado.

\begin{abstract}
It was identified a market segment that values the artichoke, that is why the business plan was elaborated, which allowed us to evaluate the possibilities of success of the business idea. It was been determined the market segment in the socioeconomic layer A and B of the provinces of Lima and Callao which represents 7551370 inhabitants, in 2005, the qualified suitable market 1056587 inhabitants, which are found in the most representative districts: Santiago de Surco, Lima, San Borja, San Miguel, Miraflores, Pueblo Libre, Jesus Maria, La Molina, San Isidro, La Victoria and Lince. The penetrated market will represent $10 \%$ with an unsatisfied demand of 8,5 MT of the final product per year. The decision of mixing the marketing is the following: Product, bottom of artichoke in syrup in $250 \mathrm{~g}$ flasks, price S/. 3,50 per flask, exclusive plaza at supermarkets E. Wong and Santa Isabel, promotion with impellers or advancers.
\end{abstract}

Key words: business plan, artichoke, market research.

' Facultad de Ingeniería en Industrias Alimentarias. Universidad Nacional del Centro del Perú.

${ }^{2}$ Investigadora libre. 


\section{INTRODUCCIÓN}

Cuando se desarrollan nuevos productos, es necesario desarrollar un plan de negocios, documento que permite en forma ágil, conocer y visualizar, las características y bondades que tiene un negocio, por lo tanto la elaboración del presente plan se integra con la propuesta tecnológica realizada para los fondos de alcachofas en almíbar. El objetivo fue realizar un plan de negocio para los fondos de alcachofa en almíbar.

\section{MATERIAL Y MÉTODOS}

El producto, se elaboró con alcachofas con espinas conocidas como criolla, cosechadas en la micro cuenca del río Achamayo; en la provincia de Concepción del departamento de Junín. Para la industrialización, se utilizó la propuesta del estudio tecnológico realizado el año 2003 por los mismos autores (1). En lo referente a la comercialización, se evaluó I o s c a n a l e s d e comercialización existentes, supermercados E. Wong y Santa Isabel.

Análisis del Entorno, se realizó u tilizando información secundaria, para el ámbito político, legal; económico, financiero; social, cultural y tecnológico. En el Análisis estructural del entorno competitivo, se utilizó información primaria y secundaria. El Análisis interno, se realizó con información primaria. En la Investigación de mercados, se escogió el segmento constituido por los estratos socioeconómicos Alto y Medio Alto, de la provincia de Lima y de la provincia constitucional del Callao, se

Tabla 1: Análisis Externo - Escenario Futuro 2010

\begin{tabular}{|c|c|}
\hline Ámbitos & Descripción \\
\hline $\begin{array}{l}\text { Político - } \\
\text { Legal }\end{array}$ & $\begin{array}{l}\text { Cae el modelo liberal. } \\
\text { El presidente en el } 2006 \text {, sería un desconocido, con un modelo más de } \\
\text { izquierda, con un modelo social de mercado. } \\
\text { Sector Público más pequeño. } \\
\text { La recaudación tributaria se hará más efectiva. } \\
\text { Mayor conciencia para proteger y conservar el medio ambiente, para } \\
\text { toda actividad que se quiera realizar. }\end{array}$ \\
\hline $\begin{array}{l}\text { Económico - } \\
\text { Financiero }\end{array}$ & $\begin{array}{l}\text { El crecimiento del PBI del año } 2010 \text { llegará al } 6 \% \text {, en forma sostenida. } \\
\text { El PBI del sector agropecuario se mantendrá casi constante por encima } \\
\text { del promedio general. } \\
\text { La balanza comercial se mantendrá positiva, por la producción nacional } \\
\text { de productos que se importaban. } \\
\text { La tasa activa en moneda nacional (TAMN), y la tasa activa promedio } \\
\text { en dólares (TAMEX), se reducirá acercándose a los valores } \\
\text { internacionales. } \\
\text { Sectores atractivos: Agroindustria, turismo, minería y pesqueria, } \\
\text { generadores de empleo. } \\
\text { Modelos macroeconómicos de rasgos heterodoxos. }\end{array}$ \\
\hline $\begin{array}{l}\text { Social - } \\
\text { Cultural }\end{array}$ & $\begin{array}{l}\text { En el año } 2010 \text { habrán } 29886000 \text { habitantes. Disminución de la } \\
\text { población agrícola. Aumento de la población económicamente activa. } \\
\text { Crecimiento de la población adulta y anciana. Nivel de población infantil } \\
\text { se mantiene. } \\
\text { La microempresa seguirá generando ocupación a más de } 2 \text { terceras } \\
\text { partes de la población que cuenta con empleo. } \\
\text { Nuevos pobres (clases medias bajas pasan a clases bajas). } \\
\text { Mayor preocupación por la salud y la educación, con atención al } \\
\text { consumo de productos naturales y sin conservantes. }\end{array}$ \\
\hline Tecnológico & $\begin{array}{l}\text { Los paquetes tecnológicos se harán de tamaños más pequeños y más } \\
\text { flexibles, en los cuales el tamaño mínimo eficiente será acorde a } \\
\text { tamaños de mercados pequeños. } \\
\text { Aumentará la automatización de la Plantas industriales. } \\
\text { Los costos inherentes a la industria conservera, se reducirá, debido a } \\
\text { una reducción de envases y de combustible. }\end{array}$ \\
\hline Ecológico & $\begin{array}{l}\text { Exigencias de implementar e implantar el sistema HACCP, e ISO } \\
14000 \text {. }\end{array}$ \\
\hline
\end{tabular}

\section{Elaboración propia.}

\section{RESULTADOS}

\section{Clientes}

- Nuevos clientes, especialmente diabéticos, habiéndose determinado que la diabetes en todas las latitudes ya no es una enfermedad, sino una epidemia.

- Nuevos valores claves: ecológico, sin aditivos químicos, las propiedades sensoriales seguirán siendo claves.

s

utilizó los planos estratificados de Lima Metropolitana a nivel de manzanas (2). Para la investigación de mercado se tomó información de (3). 


\section{Proveedores}

Mayor exigencia en el manipuleo y transporte de insumos y materias primas.

- Nuevos proveedores: aparición de nuevos latifundistas (proyectos especiales como: Chavimochic, Majes, etc.).

\section{Segmentación de mercado}

La variable de segmentación es la demográfica y psicográfica, por ingresos, ocupación, educación y clase social, constituidos por los estratos

de Lima y Callao. El mercado potencial estará conformado por la población del segmento, sabiendo que estos estratos, crecen anualmente en promedio a un nivel del $1,8 \%$, se realizó la proyección para el año 2005, el segmento de mercado será de 1604284 habitantes, y que un hogar estará conformada por 4,16 habitantes; el mercado potencial representa el 21,24\% del mercado total.

El mercado disponible calificado, estará conformado por los distritos más representativos del segmento, referido a su participación de habitantes y son los siguientes: Santiago de Surco Tabla 2: Análisis de la competencia.

\begin{tabular}{|c|c|c|c|}
\hline $\begin{array}{l}\text { FUERZAS DE } \\
\text { PORTER }\end{array}$ & PRODUCCIÓN & INDUSTRIALIZACIÓN & COMERCIALIZACIÓN \\
\hline \multirow[b]{2}{*}{$\begin{array}{l}\text { Intensidad } \\
\text { de la } \\
\text { rivalidad } \\
\text { entre los } \\
\text { competidores } \\
\text { actuales }\end{array}$} & \multirow[b]{2}{*}{$\begin{array}{l}\text { Relativamente } \\
\text { alto por lo } \\
\text { fragmentado de } \\
\text { las unidades } \\
\text { productivas. }\end{array}$} & Baja rivalidad. & \multirow[b]{2}{*}{$\begin{array}{l}\text { Santa Isabel y E. Wong, } \\
\text { empresas posicionadas } \\
\text { en el mercado, entre ellas } \\
\text { existe una mediana } \\
\text { rivalidad. }\end{array}$} \\
\hline & & $\begin{array}{l}\text { No existe productores de } \\
\text { fondos de alcachofa en } \\
\text { almíbar, los que podrian } \\
\text { calificarse como } \\
\text { competidores actuales } \\
\text { serian los productores de } \\
\text { frutas en almibar. }\end{array}$ & \\
\hline $\begin{array}{l}\text { Amenaza de } \\
\text { nuevos } \\
\text { competidores }\end{array}$ & $\begin{array}{l}\text { Pequeña, por el } \\
\text { know how en el } \\
\text { cultivo de la } \\
\text { alcachofa. }\end{array}$ & $\begin{array}{l}\text { Regular, por la existencia } \\
\text { de productores de otras } \\
\text { presentaciones de } \\
\text { alcachofa, que podrian } \\
\text { ingresar. }\end{array}$ & $\begin{array}{l}\text { Pequeña, por las altas } \\
\text { barreras establecidas por } \\
\text { inversiones de capital, } \\
\text { economias de escala, } \\
\text { diferenciación por } \\
\text { servicio, curva de } \\
\text { experiencia. }\end{array}$ \\
\hline $\begin{array}{l}\text { Amenaza de } \\
\text { productos } \\
\text { sustitutos }\end{array}$ & $\begin{array}{l}\text { Pequeña. El } \\
\text { sustituto más } \\
\text { cercano es la } \\
\text { alcachofa sin } \\
\text { espinas, pero } \\
\text { esta orientado al } \\
\text { mercado } \\
\text { externo. }\end{array}$ & $\begin{array}{l}\text { Regular. Existen otros } \\
\text { sustitutos como son las } \\
\text { conservas de fondos y } \\
\text { alcachofines en solución } \\
\text { salina y marinados. Como } \\
\text { también pastillas o } \\
\text { medicinas nutritivas. }\end{array}$ & $\begin{array}{l}\text { Baja, porque no existe } \\
\text { otro tipo de } \\
\text { comercialización con los } \\
\text { servicios ofrecidos por los } \\
\text { supermercados. }\end{array}$ \\
\hline $\begin{array}{l}\text { Poder de } \\
\text { negociación } \\
\text { de los } \\
\text { clientes }\end{array}$ & $\begin{array}{l}\text { Compartido, por } \\
\text { la alianza } \\
\text { estratégica con } \\
\text { la agroindustria, } \\
\text { mediante la } \\
\text { siembra por } \\
\text { contrato. }\end{array}$ & $\begin{array}{l}\text { Compartido, por la alianza } \\
\text { con los supermercados, la } \\
\text { agroindustria tiene que } \\
\text { negociar con producto de } \\
\text { buena calidad y servicio } \\
\text { constante a las } \\
\text { necesidades } \\
\text { insatisfechas. }\end{array}$ & $\begin{array}{l}\text { Alto, por pertenecer a un } \\
\text { segmento que conoce } \\
\text { muy bien el producto y el } \\
\text { servicio postventa que } \\
\text { esperan recibir. Debilidad } \\
\text { de los compradores, se } \\
\text { rinden fácilmente a un } \\
\text { buen trato, bastante } \\
\text { emotivos. }\end{array}$ \\
\hline Poder de & Baja, porque & $\begin{array}{l}\text { Compartido, con los } \\
\text { productores por la alianza } \\
\text { estratégica. }\end{array}$ & \\
\hline $\begin{array}{l}\text { negociación } \\
\text { de los } \\
\text { proveedores }\end{array}$ & $\begin{array}{l}\text { existen muchos } \\
\text { proveedores de } \\
\text { insumos para la } \\
\text { agricultura. }\end{array}$ & $\begin{array}{l}\text { Para otros insumos } \\
\text { propios de la } \\
\text { industrialización es baja } \\
\text { por la existencia de } \\
\text { muchos proveedores. }\end{array}$ & $\begin{array}{l}\text { Compartido, por la alianza } \\
\text { estratégica. }\end{array}$ \\
\hline
\end{tabular}

\section{Elaboración propia.}

socioeconómicos Alto y Medio Alto. Para el año 2005, se estima que el mercado total será de 7551370 habitantes, conformados por todos los habitantes
(1 1,05\%), Lima (8,19\%), San Borja (7,30\%), San Miguel $(6,42 \%)$, Miraflores (6,18\%), Pueblo Libre (4,98\%), Jesús María (4,87\%), La Molina $(4,64 \%)$, San Isidro (4,50\%), La Victoria $(4,15 \%)$ y Lince (3,57\%); sumando 1056587 habitantes. El mercado p e n e trado, e stará conformado por el 10\% del mercado disponible calificado, representando 105 659 habitantes.

De la encuesta realizada por (3), en este segmento se determinó que el consumo promedio mensual por familia es de 280 gramos de fondos de alcachofa, envasados al vacío y esterilizados.

\section{Sistema de negocio y cultura organizacional}

El sistema de negocio tiene que ver con la cadena de valor de la empresa, en la cual, las actividades primarias (logística interna, producción, logística externa, comercialización y venta, servicio post-venta); y las actividades de apoyo ( i n f r a e s t r u c t u ra, administración de recursos humanos, desarrollo de tecnología, abastecimientos). La empresa se constituirá como una sociedad anónima cerrada, para poder tener un mejor acceso a la financiación, así como el incremento de capital por el ingreso de otros accionistas. 
Como parte de la cultura organizacional se desarrollará una constante capacitación en todo lo relacionado con el procesamiento de la alcachofa, también se tiene que desarrollar niveles de compromiso con la empresa, a través de motivar la creatividad y la innovación.

\section{Riesgos}

El éxito de este negocio dependerá de los factores:

Tabla 3: Estrategia de comercialización

\begin{tabular}{|c|c|}
\hline ESTRATEGIA & CARACTERISTICAS \\
\hline \multirow{10}{*}{ PRODUCTO } & Producto esencial \\
\hline & $\begin{array}{l}\text { Fondos de alcachofa con espinas variedad criolla de diámetros } \\
\text { uniformes, y con una diferente presentación como es en almíbar. }\end{array}$ \\
\hline & Producto real \\
\hline & $\begin{array}{l}\text { Caracteristicas del producto: cabezuelas de alcachofines con diámetros } \\
\text { de } 5 \text { a } 6 \mathrm{~cm} \text {. de diámetro para el mercado de los estratos } \\
\text { socioeconómicos alto y medio alto de Lima y Callao, fondos sin } \\
\text { defectos, bien refinadas, almíbar de cubierta límpido sin partículas en } \\
\text { suspensión. }\end{array}$ \\
\hline & $\begin{array}{l}\text { Envase: frascos de vidrio de capacidad de } 250 \mathrm{~g} \text {., con las cuales se } \\
\text { tiene las conservas, envase inocuo y permite observar el producto. Con } \\
\text { fecha de elaboración y de vencimiento, código de barras, información } \\
\text { nutricional, relación de ingredientes, información al consumidor, etc. }\end{array}$ \\
\hline & $\begin{array}{l}\text { Marca: Artichoke nice, registrada en INDECOPI, que permitirá } \\
\text { desarroliar el posicionamiento del producto. }\end{array}$ \\
\hline & Calidad: Extra, por caracteristicas del producto y de su procesamiento. \\
\hline & $\begin{array}{l}\text { Inocuidad: Garantizado por buenas prácticas de manufactura, higiene y } \\
\text { el plenn fincinnamiento del sistema HACCP }\end{array}$ \\
\hline & Producto ampliado \\
\hline & $\begin{array}{l}\text { Servicio post-venta: Información completa a través de línea telefónica e } \\
\text { Internet, atención inmediata a reclamos y dudas. }\end{array}$ \\
\hline \multirow[t]{2}{*}{ PRECIO } & $\begin{array}{l}\text { El precio se establece, siguiendo la estrategia de descremado de } \\
\text { mercado, el frasco de } 250 \mathrm{~g} \text {. en S/. } 3,50 \text {. }\end{array}$ \\
\hline & $\begin{array}{l}\text { Canales de distribución, el canal será indirecto a través de los } \\
\text { supermercados Santa Isabel y E. Wong, ubicadas en los distritos } \\
\text { elegidos. }\end{array}$ \\
\hline \multirow{4}{*}{ PLAZA } & La intensidad de distribución será exclusiva en estos supermercados. \\
\hline & $\begin{array}{l}\text { Distribución física, el transporte lo realizará la empresa hacia los } \\
\text { supermercados. }\end{array}$ \\
\hline & $\begin{array}{l}\text { Control de inventarios, se aplicará el sistema justo a tiempo con un } \\
\text { inventario igual a la producción de un día. }\end{array}$ \\
\hline & Publicidad, Se realizará en los puntos de venta en los supermercados. \\
\hline PROMOCIÓN & $\begin{array}{l}\text { Promoción, Se realizará mediante impulsadoras en los momentos en } \\
\text { que las ventas comiencen a decaer. }\end{array}$ \\
\hline
\end{tabular}

Elaboración propia.

Posicionamiento del producto, el riesgo que se corre es no lograr el posicionamiento del producto,

I por lo que el lanzamiento del producto tienen que estar apoyados por una fuerte promoción. También tiene que ir acompañado de una buena mezcla de promoción, donde hay que privilegiar el producto, en sus características de calidad y de inocuidad. Financiación, la inversión total para este negocio es de $\$ 66$ 600, de la cual se financiará el 75\% que asciende a (\$49 950), el 25\% será aportado por los inversionistas. Las condiciones para el financiamiento son las siguientes:
Interés: $5,39 \%$ trimestral (Banco Wiese Sudameris), plazo de gracia: 4 trimestres, número de cuotas: 16; plazo: 4 años.

Se tiene los siguientes resultados de la evaluación económica financiera:

VANE $=$ US $\$ 74391,61$
TIRE $=27 \%$
PRIE $=5$ AÑOS
B/C $=1,37$
VANF $=$ US $\$ 95980,45$
TIRF $=66,5 \%$
PRIF $=3$ AÑOS
B/C $=1,18$

\section{DISCUSIÓN}

El escenario futuro se presenta favorable para este negocio, ya que los diferentes factores externos están mejorando para la agroindustria en general, las oportunidades se $\mathrm{p}$ u ed e $\mathrm{n}$ a prove char desarrollando efectivamente ventajas competitivas.

En cuanto a la competencia se puede generar barreras para el sector a través de las alianzas estratégicas entre productores, industrialización y comercialización que van ha permitir tener ganancias significativas como también lo determinó (3).

El hecho de realizar el desarrollo del producto, va ha permitir el incremento del consumo, mediante una nueva forma de presentación, lo que se estima en un $10 \%$, que sería 28 gramos de fondos alcachofas en almíbar. El número de familias pertenecientes al mercado 
penetrado será de 25399 , con un consumo de 28 gramos, se tiene que la demanda mensual será de 711 kilos. Lo que permite determinar el tamaño de Planta de 8,5 TM de producto final al año, lo que significa que se necesitará 29,75 TM de materia prima (cabezuelas de alcachofa). Con la estrategia de comercialización se posicionará la marca del producto y esta acorde al perfil del segmento elegido. De la evaluación económica financiera, se ve que es favorable para su ejecución.

\section{REFERENCIAS BIBLIOGRÁFICAS}

1. Seguil C, Egas E. Determinación de parámetros óptimos en la elaboración de conservas de fondos de alcachofa (Cynara scolymus) en almíbar. Instituto de Investigación. Facultad de Ingeniería en Industrias Alimentarias. Universidad Nacional del Centro del Perú. Huancayo; 2003.

2. Instituto Nacional de Estadística e Informática. Planos estratificados de Lima metropolitana a nivel de manzanas, según estratos socioeconómicos de los hogares. Editorial Monterrico S.A. Perú; 1998.

3. Seguil C. Evaluación de la competitividad en la industrialización y comercialización de la alcachofa en el departamento de Junín. Universidad Nacional Agraria La Molina; 2002. 